\title{
140 DIETARY CONSUMPTION PATTERN OF SELECTED COMMONWEALTH PROBABLES WITH SPECIAL REFERENCE TO ENERGY AND PROTEIN
}

Deethu Sara Varghese, ${ }^{1}$ Venkataramana Yagnambhatt, ${ }^{1}$ Ashok Ahuja ${ }^{1}$ Department of Work Physiology and Sports Nutrition, National Institute of Nutrition, Hyderabad, Andhra Pradesh, India; ${ }^{2}$ National Institute of Sports, Patiala, Punjab, India

\subsection{6/bjsm.2010.078725.140}

Optimal nutrition is important for athletes to maintain good performance and to attain a good health in latter life. The nutrient intake of an athlete should be adequate to cover the specific energy requirement of the sport as well as for tissue maintenance and repair. The nutritional data of international level athletes is sparse in India. Therefore, a case based study was done on the representative sample from boxing, wrestling and athletics who were preparing for commonwealth games (commonwealth probables) during the initial stage of the camp. A detailed study was done on the dietary consumption pattern of these athletes, especially on energy and protein intake levels. Both the protein and energy intake was found to be higher than the recommended levels. Even, cases in which the energy intake was found to be twofold and protein intake, more than fivefolds of the requirement was found when the nutritional data of the athletes were analysed individually. Despite of meeting their requirement of energy and protein from the diet alone, athletes were found to be consuming high amount of protein supplements. This extreme pattern of protein consumption will have deleterious effects on performance and health of the athletes. Hence, necessary dietary modifications were made to bring their energy and protein consumption to the recommended levels. It can be concluded that supplementation of energy and protein is not required if an athlete is consuming a balanced diet. To achieve this, proper awareness on nutrition should be imparted to the athletes and coaches. 